\title{
The Relationship between Aminosugars in the Lipopolysaccharide, Serotype, and Aerugino cin Sensitivity in Strains of Pseudomonas aeruginosa
}

\author{
By SUSAN F. KOVAL AND PAULINE M. MEADOW \\ Biochemistry Department, University College London, London $W C_{\mathrm{I}} E 6 B T$
}

(Received 29 July 1975)

INTRODUCTION

In a survey of the strains of Pseudomonas aeruginosa used in the Habs (I957) serotyping system we correlated aminocompound content of the lipopolysaccharides (LPS) with serotype (Chester, Meadow \& Pitt, I973). All the LPS contained alanine, glucosamine and galactosamine, but many could be distinguished by the presence of additional aminocompounds. These were detected by automatic aminocompound analysis, designated UI and U8, but not further identified. We suggested that $\mathrm{U}_{3}$ might be quinovosamine and $\mathrm{U}_{4}$ fucosamine, but without markers were unable to confirm this. We have now re-examined the Habs type strains and a few others to identify the major unknown compounds. We have also tested their aeruginocin (pyocin) sensitivity since Suzuki (1974) reported that sensitivity of $P$. aeruginosa to the aeruginocin from strain PI6 is correlated with the presence of quinovosamine in the LPS.

\section{METHODS}

Pseudomonas aeruginosa strains. The Habs serotyping strains I to I3 and strain PACI were described previously (Chester et al. 1973). Strains NCTC7244, NCTC8505, NCTC8203, NCTC8060, NCTCI0332 and NCIB8626 were those used by Wilkinson \& Galbraith (I975). Strains PI 4 and PI6 were those described by Suzuki (I974). Strain PAC605 was a spontaneous mutant resistant to PI6 aeruginocin. The aeruginocin preparations induced the lytic cycle of the lysogenic bacteriophage PSI carried by PACI. Strain PAC605 was therefore derived from a spontaneous mutant of PACI resistant to PSI. This mutant, PACIR, was otherwise indistinguishable from PACI in all properties tested including serotype, bacteriophage and aeruginocin sensitivity, and LPS structure (Chester \& Meadow, 1975).

Growth of bacteria and analysis of lipopolysaccharides. Bacteria were grown, LPS isolated and aminocompounds detected as described by Chester et al. (I973). Fucosamine and quinovosamine were isolated from PI 6 and PI 4 LPS respectively by ion exchange chromatography on Dowex 50 (Wheat, I966). Their identification was confirmed by paper chromatography in solvents A and B (Chester et al. 1973) and automatic aminocompound analysis.

Aeruginocin preparation and sensitivity. Crude aeruginocin preparations were made from PI 6 by mitomycin induction and titrated by doubling dilutions as described by Govan (1974), except that the growth medium was nutrient broth (Oxoid No. 2). Titres of $1: 64$ were obtained. Sensitivity was determined on nutrient agar plates. A loopful of the aeruginocin was streaked on the plate and allowed to dry. Cultures to be tested were grown for $4 \mathrm{~h}$ at $37^{\circ} \mathrm{C}$ in nutrient broth and a loopful of each cross-streaked against the aeruginocin. Plates were incubated at $37^{\circ} \mathrm{C}$ and inspected after 6 and $\mathrm{I} 8 \mathrm{~h}$. 
Table I. The aminosugar composition of the lipopolysaccharide and the sensitivity to PI6 aeruginocin of strains of P. aeruginosa of different serotypes

The lipopolysaccharides were isolated, analysed and aeruginocin sensitivity determined as described in Methods. UI, 5, 6, 7, 8, X and $\mathrm{Y}$ are unidentified aminocompounds.

\begin{tabular}{|c|c|c|c|c|c|c|}
\hline \multirow[b]{2}{*}{ Strain } & \multicolumn{5}{|c|}{ Aminocompounds in LPS } & \multirow[b]{2}{*}{$\begin{array}{c}\text { Sensitivity } \\
\text { to PI } 6 \\
\text { aeruginocin }\end{array}$} \\
\hline & $\begin{array}{c}\text { Habs } \\
\text { serotype }\end{array}$ & $\begin{array}{l}\text { 2-Amino- } \\
\text { 2-deoxy- } \\
\text { galacturonic } \\
\text { acid }\end{array}$ & $\begin{array}{c}\text { Quino- } \\
\text { vosamine }\end{array}$ & Fucosamine & Others & \\
\hline I & I & 0 & + & + & U5, 6,7 & $\mathbf{s}$ \\
\hline PI4 & I & 0 & ++ & ++ & $\mathrm{U}_{5}, 6,7$ & $\mathbf{s}$ \\
\hline NCTC7244 & I & $0^{*}$ & $+^{*}$ & $t^{*}$ & . & $\mathbf{s}$ \\
\hline NCIB8626 & I & $0^{*}$ & $+^{*}$ & $+^{*}$ & & $\mathbf{R}$ \\
\hline $2 \mathrm{~A}$ & $2 \mathrm{~A}$ & 0 & 0 & tr & $\mathrm{Y}$ & $\mathbf{R}$ \\
\hline 2B & 2B & 0 & 0 & $\operatorname{tr}$ & $\mathbf{Y}$ & $\mathbf{R}$ \\
\hline 3 & 3 & + & o & $\operatorname{tr}$ & $\mathrm{Y}$ & $\mathrm{s}$ \\
\hline PACI & 3 & + & 0 & tr & $\mathbf{Y}$ & $\mathrm{s}$ \\
\hline NCTC8505 & 3 & $+^{*}$ & $0^{*}$ & o* & . & $\mathrm{s}$ \\
\hline 4 & 4 & 0 & + & + & & $\mathbf{s}$ \\
\hline $5 \mathrm{C}$ & $5 \mathrm{C}$ & o & o & + & U8 & $\mathbf{R}$ \\
\hline NCTC8060 & ${ }_{5} \mathrm{C}$ & o* & $0^{*}$ & $+^{*}$ & . & $\mathbf{R}$ \\
\hline 5D & ${ }_{5} \mathrm{D}$ & + & o & + & & $\mathbf{R}$ \\
\hline 6 & 6 & + & $\operatorname{tr}$ & $\operatorname{tr}$ & $\mathrm{U}_{\mathrm{I}}, \mathrm{X}, \mathrm{U}_{5}, 6,7$ & $\mathrm{~s}$ \\
\hline NCTCIO332 & 6 & $+^{*}$ & $\operatorname{tr} *$ & $\operatorname{tr}^{*}$ & 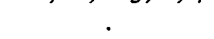 & $\mathbf{s}$ \\
\hline 7 & 7 & 0 & 0 & + & . & $\mathbf{R}$ \\
\hline 8 & 8 & 0 & o & ++ & . & $\mathrm{R}$ \\
\hline 9 & 9 & 0 & ++ & ++ & . & $\mathrm{s}$ \\
\hline 10 & 10 & + & + & $\operatorname{tr}$ & . & $\mathbf{s}$ \\
\hline I I & II & 0 & 0 & ++ & . & $\mathrm{R}$ \\
\hline PI6 & II & 0 & 0 & ++ & . & $\mathbf{R}$ \\
\hline $\mathrm{NCTC} 8203$ & II & $0^{*}$ & $\mathrm{o}^{*}$ & $+^{*}$ & . & $\mathbf{R}$ \\
\hline 12 & 12 & 0 & + & $\operatorname{tr}$ & . & $\mathbf{R}$ \\
\hline 13 & 13 & $\operatorname{tr}$ & + & $\operatorname{tr}$ & $\mathrm{U}_{5}, 6,7$ & $\mathbf{R}$ \\
\hline PAC605 & NT & $\operatorname{tr}$ & 0 & 0 & . & $\mathbf{R}$ \\
\hline
\end{tabular}

0 , Not detected; tr, less than $\mathrm{I} \cdot 0 \%(\mathrm{w} / \mathrm{w}) ;+, \mathrm{I}$ to $5 \%(\mathrm{w} / \mathrm{w}) ;++, 5 \%(\mathrm{w} / \mathrm{w}) ; \mathrm{NT}$, not typable; s, sensitive; R, resistant.

* Data taken from Wilkinson \& Galbraith (1975).

\section{RESULTS AND DISCUSSION}

\section{Aminosugar composition of the lipopolysaccharides}

The most common of the eight unidentified aminocompounds previously described (Chester et al. 1973) was $\mathrm{U}_{4}$, which we suggested might be fucosamine. When the hydrolysed lipopolysaccharides were analysed with added fucosamine, the latter co-chromatographed with U4 in all strains except type 6. This LPS contained small amounts of fucosamine but the major peak in this region of the automatic analysis $(3.5 \%$, w/w, LPS) was eluted after fucosamine and clearly separated from it. It was not detected in any other LPS and has been designated $\mathrm{X}$ in Table $\mathrm{I}$. The fucosamine from PACI was isolated by ion exchange chromatography and shown to co-chromatograph with fucosamine in solvents $\mathrm{A}$ and $\mathrm{B}$. Wilkinson and his colleagues detected fucosamine in LPS isolated from ten of the 12 strains they analysed (Wilkinson \& Galbraith, 1975; Drewry et al. 1975), and Suzuki (1974) reported fucosamine in 17 of the 22 strains of $P$. aeruginosa examined; small amounts of fucosamine may have been present in the remaining five strains since she analysed whole bacteria not isolated 
LPS. It seems likely therefore that fucosamine occurs in the LPS of most if not all strains of $P$. aeruginosa. However, the amount varies between strains and, as suggested by degradation studies, its position in the LPS may also vary (Chester et al. 1973; Chester \& Meadow, 1975; Wilkinson \& Galbraith, I975; Drewry et al. 1975).

In hydrolysates of most of the LPS previously reported to contain $\mathrm{U}_{3}$, this co-chromatographed with added quinovosamine (Table $\mathrm{I}$ ). However, automatic aminocompound analysis of the LPS from strains 2A, 2B, 3 and PACI (serotype 3 ) showed small amounts of an aminocompound eluting between quinovosamine and fucosamine but no quinovosamine. The amounts present were too small to be detected after ion exchange chromatography of hydrolysed LPS (50 mg). The compound has not been identified and is designated Y in Table I. The absence of quinovosamine in the above strains may be related to their serotype since there was no quinovosamine in the LPS from any of the five strains of serotype $2 \mathrm{~B}$ or of the strain of serotype 3 studied by Wilkinson \& Galbraith (1975). Quinovosamine appears to be part of the high molecular weight fractions released by acetic acid hydrolysis of LPS. These fractions react specifically with homologous antisera and may correspond to side chains (Chester et al. 1973; Wilkinson \& Galbraith, 1975).

Another aminocompound detected in LPS from several strains was U2. In the automatic aminocompound analysis it runs close to diaminopimelic acid, which is sometimes a minor contaminant of LPS. However, U2 could be separated from diaminopimelic acid by paper chromatography and had a much lower absorbance at $440 \mathrm{~nm}$. A compound behaving like U2 has been isolated from $P$. aeruginosa NCTC8505 LPS and identified as 2-amino-2-deoxygalacturonic acid (Wilkinson \& Welbourn, 1975). The U2 from PACI LPS was indistinguishable from this compound by paper chromatography, electrophoresis and automatic aminocompound analysis (S. G. Wilkinson, personal communication). We found 2-amino-2deoxygalacturonic acid in LPS of all strains of serotypes $3,5 \mathrm{D}, 6$, I0 and $\mathrm{I} 3$ so far analysed (Table I). We had previously reported that strain I also contained $\mathrm{U}_{2}$, but we have not found any in later batches of LPS from the same strain and must conclude that the first analysis was incorrect. It is not clear what role, if any, 2-amino-2-deoxygalacturonic acid plays in the Habs serotyping system. Like quinovosamine it is concentrated in the high molecular weight fractions of the LPS. However, mutant PAC605, which no longer reacted with specific antiserum, retained about $10 \%$ of the aminogalacturonic acid of its parent strain PACI.

\section{Aeruginocin sensitivity}

In a survey of 22 strains of $P$. aeruginosa, Suzuki (1974) found that those containing quinovosamine were"sensitive to aeruginocins from PI and PI6. Of the strains we studied most of those sensitive to PI 6 aeruginocin contained quinovosamine in the LPS, while most of the resistant strains lacked this aminosugar (Table I). However, despite their sensitivity to the aeruginocin, none of the three serotype 3 strains contained quinovosamine whereas three quinovosamine-containing strains ( $\mathrm{NCIB8626,12}$ and 13 ) were aeruginocin resistant. The resistance of some quinovosamine-containing strains to PI 6 aeruginocin does not necessarily refute Suzuki's hypothesis that the aeruginocin receptor contains quinovosamine, since in tolerant strains absorption of the aeruginocin is not followed by lysis (Holloway et al. 1973). The test for sensitivity we used does not distinguish between tolerance and resistance.

The sensitivity of the serotype 3 strains to the aeruginocin was unexpected, but none of the strains examined by Suzuki were of this serotype (N. Suzuki, personal communication). It was not a characteristic of all serotype 3 strains since, out of six such isolates obtained from different clinical sources in the Cross Infection Reference Laboratory, Colindale, London, only two were sensitive to the aeruginocin. The type-3 LPS is one of the most com- 
plex (Chester et al. 1973; Chester \& Meadow, 1975; Wilkinson \& Galbraith, 1975) and this may make these strains more aeruginocin sensitive. We have so far been unable to correlate the sensitivity of PACI to the PI6 aeruginocin with any single component of the LPS. However, LPS is probably involved in sensitivity since the spontaneous mutant resistant to PI6 aeruginocin, PAC605, has a polysaccharide-defective LPS (Koval \& Meadow, I975). Although this mutant retained $10 \%$ of the 2-amino-2-deoxygalacturonic acid of the parent strain, it lacked compound $\mathrm{X}$, fucosamine and the basic $440 \mathrm{~nm}$-absorbing compound (Chester \& Meadow, 1975) found in small amounts in the parental LPS. Therefore in PACI, resistance to PI6 aeruginocin appears to be related to changes in LPS but not to quinovosamine. It thus differs from strain PI4 in which a mutant resistant to PI5 aeruginocin and also to the PI6 aeruginocin had lost the quinovosamine in the LPS. Until we know more of the variation in structure between LPS from different strains of $P$. aeruginosa it is difficult to explain these differences.

We are grateful to the Medical Research Council for a project grant. We thank Mr P. D. Laverack for the automatic aminocompound analyses, Mr T. L. Pitt for the serotyping, and $\mathrm{Mr}$ C. J. Hubball and Mr P. Wells for excellent technical assistance. We also thank Dr S. G. Wilkinson for giving us his results before publication.

\section{REFERENCES}

Chester, I. R. \& Meadow, P. M. (1975). Heterogeneity of the lipopolysaccharide of Pseudomonas aeruginosa. European Journal of Biochemistry (in the Press).

Chester, I. R., Meadow, P. M. \& Pitt, T. L. (I973). The relationship between the O-antigenic lipopolysaccharides and serological specificity in strains of Pseudomonas aeruginosa of different O-serotypes. Journal of General Microbiology 78, 305-318.

Drewry, D. T., Symes, K. C., Gray, G. W. \& Wilkinson, S. G. (1975). Studies of polysaccharide fractions from the lipopolysaccharide of Pseudomonas aeruginosa NCTT 1999. Biochemical Journal 149, 93-106.

Govan, J. R. W. (1974). Studies on the pyocins of Pseudomonas aeruginosa: morphology and mode of action of contractile pyocins. Journal of General Microbiology 80, I-I5.

HABS, I. (1957). Untersuchungen über die O-antigene von Pseudomonas aeruginosa. Zeitschrift für Hygiene und Infektionskrankheiten I44, $218-228$.

Holloway, B. W., Rossiter, H., Burgess, D. \& Dodge, J. (1973). Aeruginocin tolerant mutants of Pseudomonas aeruginosa. Genetic Research 22, 239-253.

Koval, S. F. \& Meadow, P. M. (1975). Lipopolysaccharide-defective mutants of Pseudomonas aeruginosa PACI. Proceedings of the Society for General Microbiology 3 (in the Press).

Suzuki, N. (1974). Correlation between pyocin-sensitivity and 2-aminosugar composition of Pseudomonas aeruginosa. FEBS Letters 48, 301-305.

WheAT, R. W. (1966). Analysis of hexosamines in bacterial polysaccharides by chromatographic procedures. In Methods in Enzymology, vol. 8, pp. 60-78. New York: Academic Press.

Wilkinson, S. G. \& Galbraith, L. (1975). Studies of lipopolysaccharides from Pseudomonas aeruginosa. European Journal of Biochemistry 52, 331-343.

Wilkinson, S. G. \& Welbourne, A. P. (1975). 2-Amino-2-deoxygalacturonic acid in lipopolysaccharides from Pseudomonas aerwoinn.sn. Biochemical Journal 149, 783-714. 